\title{
Antecedents for Building Trust in Professional e-Services
}

\author{
Dieter Fink \\ Edith Cowan University, Perth, Australia \\ d.fink@ecu.edu.au
}

\begin{abstract}
Professional service providers are exploiting the web to deliver eservices to a larger but also more diverse client base. This has increased the need for building trust between them and their clients and within the firm itself. In this paper the antecedents of trust are identified and matched against strategies that public accounting practices could adopt to build trust. Eleven antecedents for external relationships ranging from trustworthiness to benevolence are identified. A key strategy is to display information about the firm's expertise, standards and clients on the website. Trust for internal relationships range from the individual to inter-firm alliances and largely rely on providing technological (Internet) support and information about the firm's vision and values.
\end{abstract}

\section{Introduction}

The question of trust has occupied our minds for many decades. In 1958 Morton Deutsch wrote, "The significance of the phenomenon of trust and suspicion in human life is attested to not only by past preoccupations but also by current problems." (p. 265) Today we can categorise as a 'current problem' the trust or lack of it associated with doing business on the Web. In this paper we will again examine the concept of trust and apply it to the environment and needs of Public Accounting (PA) practices endeavouring to offer e-services on the World Wide Web (Web).

The Web offers PA firms the potential to advise clients through electronic communication channels rather than in face-to-face meetings in the traditional office environment. The Web has the capability of providing continuous service by offering access to information around the clock and globe in multiple languages. Furthermore, it can do this in a static or interactive mode. The former is suitable for the provision of intelligence (information) services while the latter supports consulting and counselling types of services. A Web site can also contain links to other Web sites and thereby facilitate relationship networking and inter-firm alliances.

Please use the following format when cithing this chapter:

link, D., 2007, in IFIP International Iederation for Information Processing, Volume 252, Integration and Innovation Orient to L-Society Volume 2, eds. Wang, W., (Boston: Springer), pp. 41-49. 
A closer examination of the characteristics of PA e-services readily establishes the need for trust. The following are some examples. First, there is the principle that diversity results in less reliance on interpersonal similarity, common background and experience (Mayer et al, 1995). Diversity is a key feature of the many disparate types of PA clients who can be found all over the world. Second, with e-services, clients can choose from a wide range of service providers available anywhere in the world. Furthermore, PA firms can form strategic alliances with other firms to overcome their deficiencies (e.g. intelligence sharing) or exploit market opportunities beyond their means by becoming a bigger virtual organization. The diversity of opportunities for e-services increases the need for trust

\section{Underlying Assumptions for Trust}

In an attempt to provide suitable definitions for trust, one needs to establish the underlying assumptions from which they can be developed. According to Tyler and Kramer (1996), trust can be viewed from an instrumentalist and non-instrumentalist perspective. The instrumentalist model reflects rational behaviour while the noninstrumentalist model applies to social relationships. If one accepts that e-service is essentially about maximizing one's business opportunities, then the instrumentalist model appears to best meet the requirements of e-service. Furthermore, people behave rationally and "people's decisions about whether to cooperate - for example, their willingness to trust others - are based on their estimates of the probability that others will reciprocate that cooperation." (Tyler and Kramer, 1996, p. 10)

The instrumentalist model focuses on the efforts of self-interested individuals to achieve optimum outcomes in interactions with others along two principles. First, trust is a calculation of the likelihood of future co-operation (Williamson, 1993, referenced in Tyler and Kramer, 1996). "As trust declines, people are increasingly unwilling to take risks, demand greater protection against the possibility of betrayal, and increasingly insist on costly sanction mechanisms to defend their interests." (Tyler and Kramer, 1996, p. 4) Should trust decline in long term relationships between service provider and client, transaction costs increase because of the need for self-protective actions.

Second, trust is determined by the 'reputational' market and the 'shadow of the future' (Axelrod, 1984, referenced in Tyler and Kramer, 1996). In other words, unsatisfactory performance by a service provider will lead to a decline in the provider's reputation and cast a shadow over future dealings between client and the provider. With the growth in the size of the market the effectiveness of the reputational market declines as service providers and clients can now be more physically apart. As stated earlier, the Web has enabled PA practices to attract clients from anywhere in the world.

The instrumentalist perspective of trust has two implications for e-services. One, risk assessment is critical to doing business on the Web and hence increasing attention is being given to measures to minimise risk exposure. The anonymity offered by the Web provides scope for unethical and criminal behaviour. Requirements such as professional accreditation in the PA sector ensure that clients' interests and rights are being protected. Two, e-service has seen a tremendous growth in market size (its spans the globe) and hence has reduced the effect of the 
'reputational market'. However, at the same time, its is easy to communicate dissatisfaction with services received over the web and it is therefore critical that the PA practice operates professionally at all times or suffer the loss of clients.

\section{Building Trust with Clients}

Figure 1 provides a schematic overview of the main characteristics of a PA practice. The practice is made up of professionals who operate as individuals or as teams in providing services to their clients. Before being able to practice their profession, a PA has to undergo extensive education, typically at a university, to acquire the necessary knowledge and skills in accounting and related fields such as auditing, finance, taxation. When joining a firm, the novice PA gains experience under the supervision of an already qualified PA. Knowledge, skill and experience are all required to become a qualified PA. The levels of expertise required are laid down in the standards produced by the sectors professional body. It also provides guidelines on professional conduct of its members. Since individual firms may not have all of the necessary expertise required by its clients, they often form alliances with other firms in a network of PA practices.

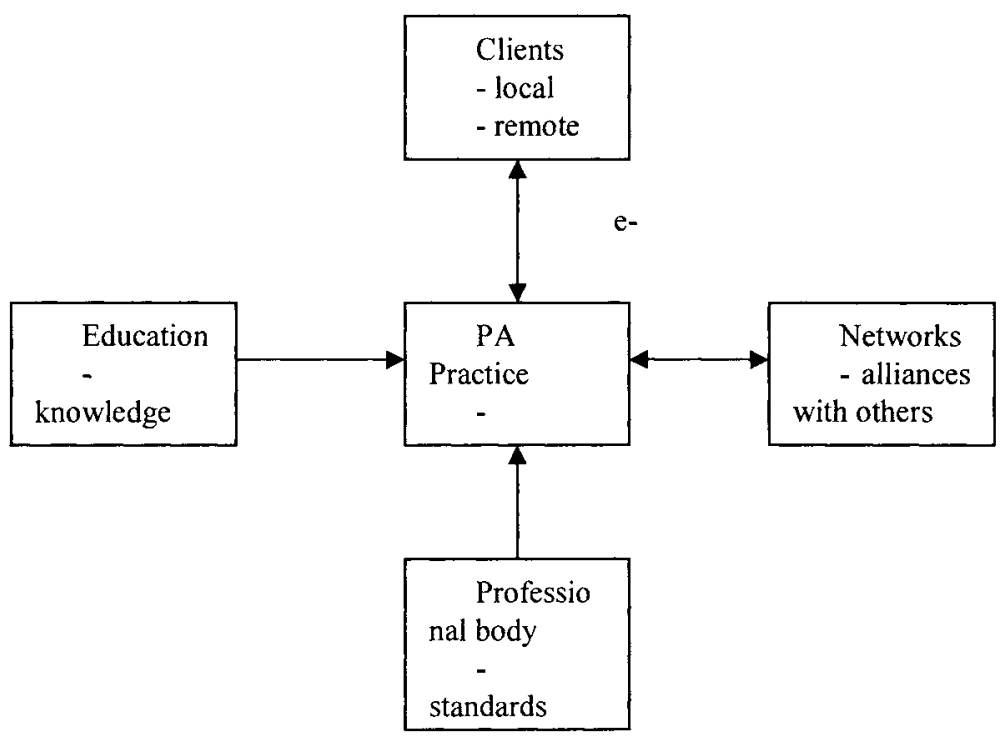

Figure 1 Schematic of Public Accounting Practice

As indicated earlier in the paper, trust is essential to establishing successful eservices because of the great diversity that now exists. However, to operationalise the meaning of trust is difficult because there have been numerous attempts to define 
and provide meaning to trust and no 'global' definition or complete acceptance of relevant antecedents for trust exist. Butler (1991, p. 647, cited in Hosmer, 1995) commented that "there is no agreement as to what these trust conditions are, and there is no instrument for measuring an exhaustive set of them." Instead, "Several terms have been used synonymously with trust, and this has obfuscated the nature of trust." (Mayer at al, 1995, p. 712) Below is an outline of the antecedents (conditions and determinants) that have been associated with trust (Fink, 2000) and how they may be relevant to PA e-services.

\subsection{Trustworthiness}

Trust is most often linked with trustworthiness. According to Deutsch (1958), trust exists when the trustworthy person is aware of being trusted and he/she is somehow bound by the trust invested in him/her. The person is 'responsible' for the trust of another. Motivation to be responsible, according to Deutsch (1958), can come from a positive sentiment towards the other and wanting the other one's goal to be realised, a fear of punishment if one is not responsible, and when one's internalised values makes one responsible. In the PA sector, internalised values (those of a PA) are generated through education and training while irresponsible behaviour would be penalised by the professional body. In the online environment, these aspects should be clearly articulated on the firm's website.

\subsection{Integrity}

"The relationship between integrity and trust involves the trustor's perception that the trustee adheres to a set of principles that the trustor finds acceptable." (Mayer et al, 1995, p. 719) In PA, guiding principles form a significant role. First, they are reflected in the education the PA undertakes. Second, various standards are developed by the profession itself and they are continually refined in response to the changing environment. A high level of initial education (at university) combined with ongoing adherence to up-to-date standards through continuous professional education should ensure that the client can rely on the integrity of performance of the service provider. Again, this information should be displayed on the website.

\subsection{Ability}

"Ability is that group of skills, competencies, and characteristics that enable a party to have influence within some specific domain" (Mayer et al, 1995, p. 717). It is reflected in the capacity of the PA practice to show that it understand the needs of the client and is able to offer solutions to problems. Demonstrating this competence has to be carried out in a persuasive manner since there is an expectation of technically competent role performances from the PAs involved. However, the difficulty is that most clients are unable to critically evaluate the competencies of specialists, such as PAs. An effective way to demonstrate ability online is to display testimonials provided by clients on the website. 


\subsection{Reliability}

Hart and Saunders (1997) outlined the role of reliability, which they perceive as consistency between what a firm says and does. Reliability reinforces and strengthens co-operation and high levels of co-operation reinforce trust. Barber (1983, referenced in Hosmer, 1995) relates this to expectation of the persistence and fulfilment of the natural and existing social order. In other words, a person would expect the world to continue without discontinuous change. In PA, reliability is taken for granted since the execution of a service has to be in accordance with current standards. For example, the service provider cannot deviate from existing taxation laws when offering taxation advice. By providing information about the PA firm's ability to comply with laws, etc, increases the perception of reliability.

\subsection{Confidence}

A number of researchers have equated trust and confidence or implied that trust was synonymously with confidence (Hosmer, 1995, referencing Deutsch, 1958; Zand, 1972; Golembiewski and McConkie, 1975). However, the distinction of trust and confidence depends on perceptions. A useful approach is to link the two concepts with risk. Luhmann (1988, referenced in Mayer et al, 1995) associated trust with risk while confidence is not associated with risk. One can illustrate this distinction as follows. If a client chooses to accept advice from the service provider without seeking the opinion of another PA, he/she is ignoring risk and one could argue that the person is in a situation of confidence. On the other hand if the client chooses the advice of one in preference to others because of an assessment of the respective levels of risk the situation can be defined as one of trust. One way to increase confidence is to publish the size and complexity of the client base that already uses e-services.

\subsection{Co-operation}

Trust and co-operation are often used synonymously although one can co-operate with someone who is not trusted. According to Powell (1996) trust increases in cooperative situations through routinising contact between parties, reducing errors, and allowing for adjustment in the relations. Yearly audit work carried out by PAs demonstrate clearly the requirement for trust; both client and provider want to ensure correct annual reporting, standards require diligent compliance from the auditor, and it is difficult and costly for the client to change auditors in an ad hoc manner because of the need to bring the incoming auditor 'up to speed'. To maintain maximum cooperation, it may be necessary to complement online with regular physical contact.

\subsection{Predictability}

The distinction between predictability and trust is ambiguous. Mayer et al (1995) held the view that trust goes beyond predictability. "To equate the two is to suggest that a party who can be expected to consistently ignore the needs of others and act in a self-interested fashion is therefore trusted" (p. 714). In other words, trust needs 
more than predictability since self-interest for example would causes a lack of trust. In PA, predictability is governed by the expected behaviour of the service provider. The client can expect that the provider performs his/her role by strictly adhering to the profession's codified conduct guidelines and responsibilities. Again, providing information about this on the website will increase trust in e-services.

\subsection{Dependence}

Trust can be viewed as the reliance on another person under conditions of dependence and risk. Dependence is experienced when outcomes are contingent on the trustworthy or untrustworthy behaviours of another while risk is determined by the experience of negative outcomes from the other person's untrustworthy behaviour (Kipnes, 1996). Dependence on the actions of others will vary by task, the situation and the person. In PA, the client very much depends on the provider giving the best advice based on the provider's advanced knowledge and experiences. The website should provide information on the credentials of the service provider, i.e. qualifications and experiences.

\subsection{Openness}

Hart and Saunders (1997) defined openness as the willingness to listen to new ideas and share rather than withhold information. This behaviour reinforces trust by reducing the probability that the service provider will behave opportunistically. PA often act in a pro-active manner, informing their clients of new developments and opportunities that may benefit them. However, such openness should be practised to the advantage of all clients rather than selected ones. It is therefore important that PA firms make information and advice accessible to all clients via their website.

\subsection{Caring}

Openness as outlined above is linked with the concept of caring. According to Hart and Saunders (1997) caring is demonstrated by goal compatibility, "the unequivocal representation that both firms share similar, not conflicting, goals" (p. 35). In PA, both parties seek success; the provider by increasing levels of services and hence fees and the client by using the advice or information provided to improve business or professional outcomes. Caring, being a human trait, is re-enforced through human contact such as through regular provider-client get-togethers.

\subsection{Benevolence}

"Benevolence is the extent to which a trustee is believed to want to do good to the trustor, aside from an egocentric profit motive. Benevolence suggests that the trustee has some specific attachment to the trustor." (Mayer et al, 1995, p. 718) In PA, the client-provider relationship is often build over a long period and both parties get to know each other very well. Since some of the old clients may not wish to make use of e-services, it would be necessary for the provider to also continue to offer 
previous face-to-face services to show that the client's best interests are being looked after.

\section{Building Trust within the PA Practice}

As outlined earlier, a PA practice operates at different levels, namely the individual, the team, the firm and as a network with other practices. At the individual level Creed and Miles (1996, p. 33) concluded that "trust is build by trusting". This is akin to approaches used in recognised professions and highest levels of skilled artisans. "When the 'master' professional treats the apprentice as a colleague from the beginning, he or she is taking a risk in the hope that such trust will both elicit greater trustworthiness and will be returned." (Creed and Miles, 1996, p. 33) PA firms should therefore provide employees with the necessary technological support to develop into competent PAs. For example, they should be provided with Internet access to be able to carry out environmental scanning without being concerned with the misuse of the technology.

At the team level, trust needs to be part of modern self-managing teams. Trust is generated by putting teams through exercises to build awareness of common responsibilities and fostering the skills needed for self-governance. A good example is an audit team that works together in applying professional audit techniques when examining the client's financial accounts. Each team member has an important role to play in establishing the audit opinion on various systems and sub-systems they are responsible for. In the online environment, this can be achieved by linking professionals through group support systems on an intra- or extranet.

At the firm level, management should "begin the process of activating dormant preferences for cooperation" (Creed and Miles, 1996, p. 33). This means that practice views employment relationships as social as well as economic exchanges. Handy (1995) suggested that their vision and mission statements emphasise the need for learning, bonding and leadership to enhance trust. The firm's intranet would be a suitable media to display the firm's vision and values that guide professional conduct.

Collaborative networks depend on minimal transaction costs for their responsiveness and efficiency. The existence of high levels of trust allows a reduction in transaction costs (Creed and Miles, 1996). Extended business groups often share historical experiences, obligations and advantages of group membership. In Japan they are called keiretsu (meaning societies of business) where "the large networks of producers look like complex, extended families, organized either in a cobweb-like fashion or a vast holding company with financial institutions at the apex" (Powell, 1996 , p. 58). They apply the principles of obligation and reciprocity in their business dealings to generate trust. Internet technology provides the means to bring partners closer effectively (e.g. quick responses and turnaround) and efficiently (e.g. reduced transaction costs).

\section{Conclusion}

This paper has attempted to identify the antecedents of trust and applied the various perspectives to the nature of pubic accounting. Once the conditions and determinants 
of trust for e-services are know, PA firms will be able to maximize trust through adopting the strategies identified in this paper. They are summarized in Table 1. Due to the word restrictions of the paper the list of actions is not comprehensive and others could be identified. However, it provides good examples on what the PA practice may able to achieve in developing increasing levels of trust, both with their clients and within the practice itself.

Table 1: Antecedents and Strategies

\begin{tabular}{|c|l|}
\hline Antecedents & \multicolumn{1}{|c|}{ Strategies } \\
\hline Trust with clients & $\begin{array}{l}\text { Display information on website about professional training } \\
\text { and standards }\end{array}$ \\
\hline Trustworthiness & $\begin{array}{l}\text { Display information on website about continuous training } \\
\text { and adherence to professional standards }\end{array}$ \\
\hline Integrity & Display client testimonials on website \\
\hline Ability & $\begin{array}{l}\text { Display information on website about compliance with laws } \\
\text { and regulations }\end{array}$ \\
\hline Reliability & $\begin{array}{l}\text { Display on website information about size and complexity } \\
\text { of client base }\end{array}$ \\
\hline Confidence & Complement online service with regular physical meetings \\
\hline Co-operation & $\begin{array}{l}\text { Display information on website requirement to adhere to } \\
\text { professional standards and behaviour }\end{array}$ \\
\hline Predictability & $\begin{array}{l}\text { Display information on website about provider's } \\
\text { credentials, i.e. qualifications and experiences }\end{array}$ \\
\hline Dependence & Ensure that information on website is accessible to clients \\
\hline Openness & Arrange for regular get-togethers with clients \\
\hline Caring & $\begin{array}{l}\text { Continue to offer face-to-face services in addition to online } \\
\text { services }\end{array}$ \\
\hline Benevolence & $\begin{array}{l}\text { Provide technology (Internet) access for personal } \\
\text { development }\end{array}$ \\
\hline Trust within practice & Provide intranet support to link team members \\
\hline Individual & $\begin{array}{l}\text { Display information in website about firm's vision and } \\
\text { values }\end{array}$ \\
\hline Team & $\begin{array}{l}\text { Link partners through Internet to for efficiency and } \\
\text { effectiveness }\end{array}$ \\
\hline Firm & \\
\hline Alliance & \\
\hline
\end{tabular}

The consequences of ignoring, or worse loosing trust, can be severe. Within interpersonal networks, such as the one between service provider and client, trust and distrust have opposite effects, their influence is not symmetrical. Trust builds incrementally, but distrust has a more dramatic 'catastrophic' quality. Thus while we cautiously develop trust with each other, often over a lengthy period of time, a sudden, unexpected and unpleasant development can destroy the relationship. Should one of the parties have cause to loose trust in the other party it may be impossible to re-establish it.

\section{References}

1. Axelrod R. (1984) The Evolution of Cooperation, Basic Books, New York. 
2. Barber B. (1983) The Logic and Limits of Trust, Rutgers University Press, New Brunswick, NJ.

3. Butler J.K. (1991) "Toward Understanding and Measuring Conditions of Trust: Evolution of a Conditions of Trust Inventory", Journal of Management, 17(3), 643-663.

4. Creed W.E. and Miles R.E. (1996) "Trust in Organizations A Conceptual Framework Linking Organizational Forms, Managerial Philosophies, and the Opportunity Costs of Controls", in Kramer R.M. and Tyler T.R. (Eds.) Trust in Organizations - Frontiers of Theory and Research, Sage Publications, London.

5. Deutsch M. (1958) "Trust and Suspicion", Conflict Resolution, 2(4), 265-279.

Fink D. (2000) "Developing Trust for E-Commerce" in Janczewski L. (ed) Internet and Intranet Security Management: Risks and Solutions, Idea Group Publishing, London.

6. Golembiewski R.T. and McConkie M. (1975) "The Centrality of Interpersonal Trust in Group Processes" in Cooper C.L. (Ed.) Theories of Group Processes, Wiley, New York, 131185.

7. Handy C. (1995) "Trust and the Virtual Organization", Harvard Business Review, May-June, $40-50$.

8. Hart P. and Saunders C. (1997) "Power and Trust: Critical Factors in the Adoption and Use of Electronic Data Interchange", Organization Science, 8(1), 23-42.

9. Hosmer L.T. (1995) "Trust: The Connecting Link between Organizational Theory and Philosophical Ethics", Academy of Management Review, 20(2), 379-403.

10. Kipnis D. (1996) "Trust and Technology" in Kramer R.M. and Tyler T.R. (Eds.) Trust in Organizations - Frontiers of Theory and Research, Sage Publications, London.

11. Luhmann N. (1988) "Familiarity, Confidence, Trust: Problems and Alternatives" in Gambetta D.G. (Ed.) Trust, Basil Blackwell, New York, 94-107.

12. Mayer R.C., Davis J.H. and Schoorman F.D. (1995) "An Integrative Model of Organizational Trust", Academy of Management Review, 20(3), 709-734.

13. Powell W.W. (1996) "Trust-Based Forms of Governance" in Kramer R.M. and Tyler T.R. (Eds.) Trust in Organizations - Frontiers of Theory and Research, Sage Publications, London.

14. Tyler T.R. and Kramer R.M. (1996) "Whither Trust?", in Kramer R.M. and Tyler T.R. (Eds.) Trust in Organizations - Frontiers of Theory and Research, Sage Publications, London.

15. Williamson O.E. (1993) "Calculativeness, Trust, and Economic Organization", Journal of Law and Economics, 34, 453-502.Zand D.E. (1972) "Trust and Managerial Problem Solving", Administrative Science Quarterly, 17, 229-239. 